\title{
Monitoring Athlete Training Loads: Consensus Statement
}

\author{
Pitre C. Bourdon, Marco Cardinale, Andrew Murray, Paul Gastin, Michael Kellmann, Matthew C. Varley, \\ Tim J. Gabbett, Aaron J. Coutts, Darren J. Burgess, Warren Gregson, and N. Timothy Cable
}

\begin{abstract}
Monitoring the load placed on athletes in both training and competition has become a very hot topic in sport science. Both scientists and coaches routinely monitor training loads using multidisciplinary approaches, and the pursuit of the best methodologies to capture and interpret data has produced an exponential increase in empirical and applied research. Indeed, the field has developed with such speed in recent years that it has given rise to industries aimed at developing new and novel paradigms to allow us to precisely quantify the internal and external loads placed on athletes and to help protect them from injury and ill health. In February 2016, a conference on "Monitoring Athlete Training Loads-The Hows and the Whys" was convened in Doha, Qatar, which brought together experts from around the world to share their applied research and contemporary practices in this rapidly growing field and also to investigate where it may branch to in the future. This consensus statement brings together the key findings and recommendations from this conference in a shared conceptual framework for use by coaches, sport-science and -medicine staff, and other related professionals who have an interest in monitoring athlete training loads and serves to provide an outline on what athlete-load monitoring is and how it is being applied in research and practice, why load monitoring is important and what the underlying rationale and prospective goals of monitoring are, and where athlete-load monitoring is heading in the future.
\end{abstract}

Keywords: injury prevention, wearable technologies, workload, prescribing performance

Monitoring athletes' training load is essential for determining whether they are adapting to their training program, understanding individual responses to training, assessing fatigue and the associated need for recovery, and minimizing the risk of nonfunctional overreaching, injury, and illness. However, despite the recent boom in research in this area much of what is known about athlete monitoring still comes from personal experiences and anecdotal information or remains unpublished. ${ }^{1}$ To help address this issue, a conference on "Monitoring Athlete Training Loads-The Hows and the Whys" was held at the Aspire Academy, Doha, Qatar, in February 2016. The conference brought multidisciplinary experts together to share their cutting-edge applied research and

Primary affiliations: Bourdon, Cardinale, Murray, and Cable, Sport Science, and Varley and Gregson, Football Performance and Science, Aspire Academy, Doha, Qatar. Gastin, School of Exercise and Nutrition Sciences, Deakin University, Melbourne, Australia. Kellmann, Faculty of Sport Science, Ruhr-University Bochum, Germany. Gabbett, Inst for Resilient Regions, University of Southern Queensland, Ipswich, Australia. Coutts, Sport and Exercise Discipline Group, University of Technology Sydney, Australia. Burgess, Port Adelaide Football Club, Adelaide, Australia. Secondary affiliations: Bourdon and Burgess, School of Health Sciences, University of South Australia, Adelaide. Cardinale, University of St Mark \& St John, Plymouth, UK. Murray, Athletics Dept, University of Oregon, Eugene. Kellmann, School of Human Movement and Nutrition Sciences, University of Queensland, Brisbane, Australia. Varley, Inst of Sport, Exercise and Active Living, Victoria University, Melbourne, Australia. Gabbett, Gabbett Performance Solutions, Brisbane, Australia. Gregson and Cable, Research Inst for Sport and Exercise Sciences, Liverpool Johns Moore University, UK Address author correspondence to Pitre C. Bourdon at pitre.bourdon@aspire.qa. contemporary practices. This consensus paper provides a summary of the key research and practical themes presented at the conference and provides directions for future developments in training-load monitoring.

\section{Defining Training Load}

Measures of training load can be categorized as either internal or external. For the context of this paper internal training loads are defined as the relative biological (both physiological and psychological) stressors imposed on the athlete during training or competition. Measures such as heart rate, blood lactate, oxygen consumption, and ratings of perceived exertion (RPE) are commonly used to assess internal load. On the other hand, external training loads are objective measures of the work performed by the athlete during training or competition and are assessed independently of internal workloads. Common measures of external load include power output, speed, acceleration, time-motion analysis, global positioning system (GPS) parameters, and accelerometerderived parameters. A summary and evaluation of some common methods used to monitor athlete training load and/or responses are presented in Table 1.

An integrated approach to training load is also important, and for this reason internal and external training loads should be used in combination to provide greater insight to training stress. For example, athletes repeating the exact same session on different days may maintain the same power output for the same duration (ie, same external load) but experience quite different internal loads (heart rate, blood lactate, RPE, etc) depending on their state of fatigue, emotional disturbances, recent training history, or illness. This uncoupling of internal and external loads may aid in determining if an athlete is fresh or fatigued. ${ }^{1}$ 


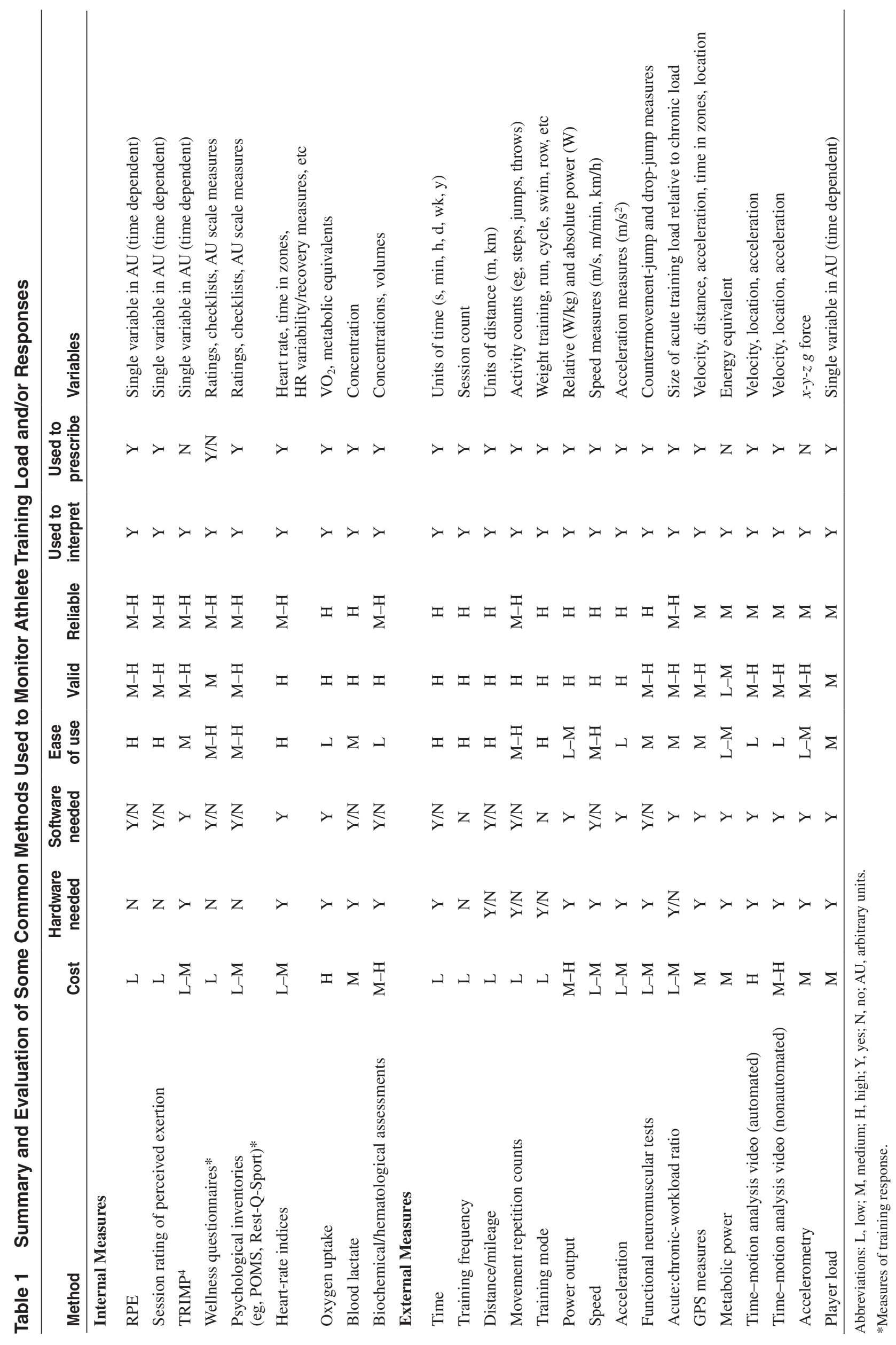




\section{How Is Training Load Monitored?}

\section{GPS Measures in Team Sports}

External training load in team sports is routinely measured using GPS. GPS devices measure distance calculated by positional differentiation. Although velocity can be derived from distance, it is more commonly calculated via the Doppler-shift method as this results in greater precision and fewer errors, ${ }^{2}$ and acceleration is subsequently derived from velocity. Due to the inherent "noise" in GPS velocity and acceleration data they are often processed using a smoothing filter in the manufacturer's software. The type of filter may vary according to manufacturer and may change with software and firmware updates. The raw or smoothed data can be exported from the manufacturer's software for custom analysis using custom-made software. Unfortunately, not all manufacturers disclose information relating to how the data are processed or allow access to raw data. Therefore, practitioners should endeavor to be aware of the type of data processing they are using and maintain consistency in their analysis methods (and indeed consistency of equipment).

The validity and reliability of GPS devices have been extensively reviewed elsewhere. ${ }^{3}$ In brief, it appears that validity and reliability for measuring distance and velocity are improved with a higher sampling frequency., 4 However, the ability of GPS to accurately measure velocity is reduced when there is a high rate of change in velocity. 5,6 Therefore, acceleration, deceleration, and directional change should be interpreted with caution. It is also difficult to determine the within-unit reliability of GPS devices using human participants as this requires precise replication of movement throughout a course or circuit. Future research assessing within-unit reliability using robotic technology to exactly replicate velocity during a task is therefore required. Furthermore, to minimize interunit variability, the same unit should be used to monitor an athlete, ${ }^{7}$ and a new validation should occur for each GPS model or after any software or firmware updates that may alter the data processing.

Typically external-load metrics derived from GPS can include the distance or number of efforts an athlete undertakes in various speed or acceleration thresholds. ${ }^{8,9}$ External-load metrics are often misinterpreted either during analysis or on communication to other sports practitioners. For example, sprint distance typically refers to when an athlete is moving faster than the sprint-velocity threshold (ie, $7 \mathrm{~m} / \mathrm{s}$ ). This differs from how a sprint is thought of during training and testing, where the sprint commences from a static start. Similarly, an acceleration effort is the time the athlete spends above a given rate of acceleration (ie, $3 \mathrm{~m} / \mathrm{s}^{2}$ ). As the rate of acceleration declines rapidly after a maximal acceleration this may only refer to the athlete's first 1 or 2 steps. It is important to delineate these metrics precisely to coaches and practitioners before they are used, especially as there seems to be an exponential growth in the number of new metrics available to users of wearable technology.

\section{Endurance Sports}

A wide variety of internal-load-monitoring methods are commonly used in endurance sports, including RPE assessments, psychological inventories, training impulse (TRIMP), and physiological measures such as heart rates and it derivatives, blood lactate concentrations, and oxygen consumption. External measures such as speed, power output, training time, and distance are also commonly used (see Table 1). Concurrent assessment of specific load measures (external and internal) allows an assessment of combined physiological and psychological stress and also allows applied researchers and practitioners to evaluate fatigue/recovery status, adjust individual training prescription, and determine relationships between these loads and performance. ${ }^{10}$ Furthermore, such metrics allow the categorization of training stimulus into relative zones of intensity (low, moderate, high).

Even though there is no single, definitive marker that can accurately quantify the fitness and fatigue responses to training, ${ }^{11}$ the development and validation of equipment and methods to quantify endurance training and competition loads have developed considerably in recent years. Key features of such systems should include ease of use and intuitive design, efficient result reporting, ability to be used remotely, translatability of data into simple outcomes, flexibility and adaptability for different sports, ability to simply and efficiently identify meaningful change, an assessment of cognitive function, and capability of providing both individual and group responses..$^{1,10}$

\section{Strength and Power Training}

Strength and power training are integral components of most training programs. Progressions of load are typically performed by recording the load lifted, the total number of repetitions completed for each load, and the calculation of total volume and intensity. ${ }^{12}$ Volume load (number of repetitions $\times$ external load $[\mathrm{kg}]$ ) has been used to monitor athletes and to quantify strength/power training loads as it does not require additional equipment and is a very convenient approach to training quantification. Such quantification has been extended by determining the mechanical work performed during resistance exercise. ${ }^{13}$ This requires the measurement of force and displacement of the barbell and/or ground-reaction force during jumping-type activities. Several methods have been suggested for this task, including video analysis, ${ }^{14,15}$ inertial sensors and accelerometers, ${ }^{16,17}$ force plates, ${ }^{18}$ linear position transducers, ${ }^{19}$ and V-scope. ${ }^{20}$

While some have shown good validity and reliability, their implementation in the applied setting has been challenging due to the cost, as well as the time and manpower requirements for collecting, analyzing, and reporting data. So far, linear encoders, inertial sensors, and accelerometers have shown promise in quantifying various aspects of training load in the gym. However, due to the proliferation of new sensors on the market and the absence of associated validity and reliability data, it is important for practitioners to exercise caution when implementing their use. It is advisable to use valid sensors in monitoring training and to ensure that the software used is performing correctly and reliably so that the resultant data can be used for meaningful inferences and comparison.

\section{Load Monitoring in Young Athletes}

The quantification of training and competition loads in children is important as evidence suggests a relationship between high volumes of training in adolescent years (13 to $14 \mathrm{y}$ ) and injury and subsequent early retirement. ${ }^{21}$ For example, young cricket fast bowlers (14.7 \pm $1.4 \mathrm{y}$ ) had 3.1 times higher injury risks when they had less than 3.5 days rest between bowling episodes. ${ }^{22}$ In addition, baseball pitchers $(8-14$ y) showed a relationship where a moderate volume of pitches was protective against injury, a low volume made no difference, and a high volume ( $>600$ pitches in a season) elicited a higher risk of injury that increased with each additional pitch. ${ }^{23}$ These studies clearly indicate that when dealing with young athletes, planning appropriate training loads and the management of loading patterns is important to guarantee a long sporting career. In addition, load 
monitoring may be more effective in preventing lost days of training, which is extremely important for training development and exposure to progressive increases in training volume.

It is recommended that young athletes keep training diaries not only with the view of understanding their training loads but also to understand the loading implications of their attendance, performance, and health. While numerous approaches can be used to quantify training, RPE-related measures should be used with caution as the ability of young athletes to self-assess their perception of load and effort can be unreliable. RPE should also not be considered in isolation but should be linked to other objective quantification methods such as volume, loads, jumps, ${ }^{24}$ or pitch counts. ${ }^{25}$ In addition, other metrics of internal loads should be implemented depending on the sport, the age, and the access to appropriate tools.

Furthermore, lifestyle factors should be quantified in young athletes, because many non-training- or non-competition-related stressors are linked to burnout and/or abandoning sport. The adolescent years are periods of high stress (family and academic commitments), and for these reasons monitoring how young athletes cope with training should employ a holistic approach, with decisions about an acceptable level of overall load taken jointly between athletes' support and family teams. This may encompass psychological measures, physiological measures (ie, heart-rate monitoring, ${ }^{26}$ acute:chronic-workload ratios $[\mathrm{ACWR}]^{27}$ ), physiotherapy measures (ie, daily screening, injury monitoring ${ }^{28}$ ), coach input (ie, record of prescribed and actual training, performance times), and conversations with the athlete. These data need to be assessed for any clinically significant changes before an informed decision is made on future training loads.

\section{Psychological Measures for Monitoring Training Loads}

Interindividual and intraindividual differences in recovery potential, exercise capacity, nontraining stressors, and stress tolerance may explain the different degrees of vulnerability experienced by athletes under identical training conditions. The key is to evaluate athletes individually, monitor them regularly, and compare the obtained data longitudinally. Overtraining studies have demonstrated that psychological indicators are more sensitive and consistent than physiological indicators. ${ }^{29}$ In addition, psychological measures can be applied and reported more quickly (minutes) than physiological or blood markers, which can take days or weeks to assess.

Common indices used within session include the Profile of Mood States ${ }^{30}$ and its derivatives (see Saw et $\mathrm{al}^{31}$ ), Borg RPE, ${ }^{32}$ session RPE (sRPE), ${ }^{33}$ and the Recovery-Stress Questionnaire for Athletes. ${ }^{34,35}$ Recently, the Acute Recovery and Stress Scale and its short version the Short Recovery and Stress Scale ${ }^{36}$ were developed to satisfy the request of sports practitioners for an economic, valid, and change-sensitive psychometric instrument to quantify recovery and stress. Saw et $\mathrm{al}^{31}$ (in this supplement) provide an overview of characteristics of various monitoring instruments used in sport science and guidelines for selecting appropriate assessment tools.

Selecting the right instrument for monitoring training loads depends on the perspective the practitioner has on the use of the data. First, the instrument needs to be valid and reliable and, ideally, come with a manual describing in detail its application and the development process and provide theoretical background and empirical data. Second, it needs to be decided if the measure is to be used for research purposes or for applied feedback to athletes and coaches. Third, the time frame of the tool is important; for example, should it be a more global (eg, past 3 days/nights) or a very specific time frame (right now). Fourth, a clear feedback loop needs to be established, and ideally a qualified practitioner will provide educational information to athletes and intervene if special circumstances arise. Fifth, the data should not be used for selection purposes; otherwise it will undermine compliance and increase the chances of faked data. Finally, an economical and conscious decision on when data are needed is important. Sometimes it is more practical to have a brief instrument on a daily or weekly basis and combine it with a longer, detailed measure when special preparation phases or competitions are completed.

\section{Why Is Athlete-Load Monitoring Important?}

\section{Applying Load Monitoring to Facilitate Coach Decision Making}

The professional world of elite sports offers unique challenges for sports-science and sports-medicine (SSM) practitioners when monitoring load and its manipulation. These challenges typically surround athlete and coach belief, the resources available, and the relationship between the applied environment and the available evidence.

The evidence on load monitoring is often collected in distant and retrospective studies performed on semielite populations. SSM practitioners wishing to apply such evidence should adapt, rather than wholly adopt, the evidence-based practices specifically to their squad and possibly conduct in-house validation of their practices. This will ensure that any results from monitoring emanate from robust practice.

A primary goal of load monitoring should be to assist and inform coach/manager decision making on player availability for training. Where possible, coach/player education on reasons for, and outcomes from, monitoring should take place at the start of every preseason. Information should be simplified, with reporting limited to a few key metrics. SSM practitioners also need to provide feedback to players and recommendations to coaches in the context of their specific circumstance. Ideally, monitoring reports should be placed appropriately in change rooms/facilities with individual feedback, rather than just group means. This not only provides further education but also demonstrates to athletes and coaches that practitioners have the ability to contextualize the results.

SSM practitioners should select both internal and external monitoring tools that suit their specific situation. Note that a combination of work performed (external load) and impact of work performed on the player (internal load) provides an assessment of the athlete's/team's capacity to handle the session delivered. If implemented longitudinally, a combination of internal and external monitoring can also provide information on training-load adaptation for both individuals and teams.

Ideally, a combination of objective and subjective tools should be employed. This ensures an equal balance between athlete perception and quantifiable practice. This is particularly important when working with a poorly educated or skeptical training group. While convenient and valid, ${ }^{37,38}$ sRPE can often be misused by athletes looking to falsely influence subsequent training sessions. In this scenario an objective form of monitoring may be more appropriate while athletes are familiarized and trained in the appropriate methods for providing sRPE.

In addition, some coaches may feel that placing monitoring devices on athletes alters their focus from skill execution to physical 
performance. In this scenario the SSM practitioner should seek other methods to quantify load, such as SRPE, coach sRPE, or heart-rate monitoring.

SSM practitioners working in elite sport environments should therefore be aware of athlete and coach preferences, as well as the available evidence on load monitoring for their sport. Practitioners should then select appropriate, specific, and even adapted methodologies to inform practice.

\section{Analyzing Training-Load Data}

One of the major challenges for scientists and coaches who collect training data is to be able to analyze them to make meaningful inferences on the efficacy of the training processes for individual athletes and coaches. Indeed, there has been a recent increase in the number of both scientific reports and case studies using various analyses of training-load data to infer on readiness to perform, risk of illness, injury risk, and return to play from injury in athletes..$^{27,39-42}$ The following section describes the common methods used to analyze these training-load data.

Fitness-Fatigue Model. The original fitness-fatigue model reported by Banister et $\mathrm{a}^{43}$ used a systems-theory approach to analyze the responses to physical training and is described as

Modeled performance $=$

fitness from training model - $K$ (fatigue from training model

where $K$ is the constant that adjusts for the magnitude of the fatigue effect relative to the fitness effect.

Several other groups have modified this initial model to account for changes in training monotony (ie, variation in training-load stimulus) and increased fatigue, ${ }^{44-48}$ but essentially each model suggests that the training impulse (or training load) elicits fitness responses that increase performance and also produce fatigue responses that decrease performance. This approach results in impulse-response models that relate training loads to performance, accounting for the dynamic and temporal characteristics of training and the effects of training over time.

Although this approach has been used to guide training planning ${ }^{49}$ and predict future performance and fitness and fatigue levels, ${ }^{42,48,50,51}$ it has been criticized for oversimplifying complex relationships between training and performance. ${ }^{52,53}$ Indeed, such models have shown large variability in parameters and precision in predicting performance in highly trained athletes.$^{52}$ In addition, these models assume a single measure to represent performance, which limits their application to sports where physical and techni$\mathrm{cal} /$ tactical performance may represent true performance. In reality, different constructs of an athlete's performance may develop or decay at different rates, and these processes are simplified by these models. Nonetheless, this approach provides a basis to set future training loads and recovery periods and to understand to general responses of athletes to training.

Acute:Chronic-Workload Ratio. The ACWR is a simplification of Banister's original fitness-fatigue, model, which uses rolling averages to compare training loads completed in a recent period (usually $\sim 5-10$ d) with the chronic training load completed over longer period (usually $\sim 4-6$ wk). 27,40 This analytical approach has recently been reported to identify injury risk in a variety of athletes. ${ }^{27,54,55}$ However, while interesting for monitoring injury risk, the validity of the ACWR has recently been questioned ${ }^{56,57}$ as the rolling average fails to account for the decaying nature of fitness and fatigue effects over time, and therefore it may not accurately represent variations in the manner in which loads are accumulated. An alternative method is to use an exponentially weighted moving average ${ }^{58}$ for the calculation of acute and chronic loads, which assigns a decreasing weighting to compensate for the latency effects of loads. ${ }^{57}$ Further research is, however, required to determine if this new model provides a superior approach for predicting performance and/or injury.

Internal:External-Load Ratio. The internal- and external-load measures available with today's microtechnology (eg, GPS) mean that measures from these devices are becoming of increasing interest to scientists and coaches as a noninvasive approach to understand how athletes are coping with training and competition. The integrated internal:external-load ratio assesses the psychophysiological stress experienced by the athlete (ie, heart rate, RPE, blood lactate, etc) during training in the context of the external training load completed and can be used to infer on athlete training status. For example, an increase in the internal load to a standard external load may infer athlete fatigue or decreased fitness, while a reduced internal load (a lower heart rate or perception of effort to a standard external load) indicates that an athlete is gaining fitness and coping with training. Furthermore, this may inform on the consequences of training programs, ${ }^{59}$ identify fatigue during team-sport competition, ${ }^{60,61}$ and identify changes in fitness or fatigue status. ${ }^{62}$ However, while practically attractive, the implementation of this approach is limited unless care is taken in controlling and quantifying the athlete's external loads ${ }^{63}$ and the environment in which the exercise is completed.

\section{Modeling Training Loads With a View to Enhance or Predict Athletic Performance}

Performance responses to training are nonlinear, influenced by a myriad of training- and non-training-related factors, and difficult to accurately predict.

Since the initial performance model suggested by Banister et $\mathrm{al}^{43}$ the systems-model approach has been used to improve the understanding of the training process and has been applied to predict an individual athlete's performance. ${ }^{11,43,46}$ Indeed, studies that used the systems-model approach to predict performance have reported a significant relationship between the modeled and actual performance in a range of sports including swimming, running, cycling, triathlon, and hammer throwing (for review see Jobson et $\mathrm{al}^{53}$ and Taha and Thomas ${ }^{64}$ ). Unfortunately, however, the broader application of this approach to predict performance in highly trained athletes is limited due to the large amount of unexplained variance in the predictions for performance across a range of endurance sports. ${ }^{42,65,66}$ Other limitations of this approach are that they fail to consider the different responses provided by all of the training stimuli (ie, internal vs external load or aerobic vs resistance load, etc), and the models have mostly been applied to individual sports. In addition, they have not yet been applied to team sports where between-matches training loads are consistent and there is a relatively small dose of training between competitions (ie, usually 1 or 2 games per week).

While the predictive accuracy of such models has since been refined with the addition of time-invariant parameters to take into account the accumulative effects of fatigue, ${ }^{44}$ they have still been unable to consistently predict an individual athlete's performance with a high level of confidence in a real-world setting. ${ }^{45,49,64}$ Moreover, these models do not account for other aspects that influence competitive performance (ie, environmental, psychological influences, pacing, etc) and may also limit their predictive capacity. Therefore from a practical point of view, these modeling techniques 
remain of little benefit for predicting future performance in highperformance athletes. Nonetheless, they do provide an important theoretical framework that allows coaches and scientists to understand and control the training process.

To overcome the limitations of the load-response models, other complex methods such as nonlinear, multilayer, perception neuralnetwork models have been proposed.$^{67}$ There have even been a few case studies that have shown this approach to markedly reduce prediction error of performances. However, the "black box" nature of these approaches prevents it from identifying important causal relationships between the training and outcome relationships, which limits their usefulness for helping coaches understand training. Other limitations of these approaches are the requirement for very large data sets of training load (including performance and other outcome measures) over extended periods, so that models can be "trained" to provide strong predictive outcomes.

Recent studies have reported simplified analysis or modeling of training-load data in a variety of athletes to make inferences on readiness to perform, ${ }^{42}$ return to sport, ${ }^{68}$ and injury risk. ${ }^{69}$ However, at present, few studies have examined the sensitivity and specificity of these models to predict performance and injury. Even with increased use of wearable sensors and enhanced ability to collect information on training load and the athlete's responses to training, future work is still required to enable scientists to make use of these large data sets and develop valid models that can be used to link training with the athletes' responses and performance.

\section{Athlete-Load Monitoring and Injury Prevention}

All practitioners involved in the training process (eg, coaches, physiotherapists, and strength and conditioning staff) are interested in identifying the optimal amount of training to elicit specific performance levels. This training "dose-response" relationship is analogous to pharmacological studies where chemists wish to understand the positive and negative effects of a particular drug. Sport scientists understand that physically hard training is required to prepare athletes for the demands of competition but are also aware that excessive loading can result in increased injury risk.

Early research reported a positive relationship between training load and injury, suggesting that the harder athletes train the more injuries they are likely to sustain. ${ }^{70,71}$ Furthermore, greater amounts of high-speed running have been associated with greater lower-body, soft-tissue injury risk, ${ }^{72}$ while reductions in training load resulted in fewer injuries and greater improvements in aerobic fitness. ${ }^{73}$ However, a significant body of evidence has emerged to demonstrate that high chronic training loads may protect athletes against injury. ${ }^{27,41,54,74-77}$ Collectively, these results suggest that training load might best be described as the "vehicle" that drives athletes toward or away from injury. ${ }^{78}$

In the first study to demonstrate the protective effect of high training loads, Hulin et $\mathrm{al}^{74}$ reported that cricket fast bowlers who bowled a greater number of balls over a 4 -week period (ie, chronic training load) had a lower risk of injury than bowlers who bowled fewer balls. These findings have subsequently been replicated across a wide range of sports (eg, rugby league, Australian football, Gaelic football) and have given rise to the ACWR (previously referred to as training-stress balance) ${ }^{76}$ (size of current training load relative to chronic). When the ACWR was in the range of 0.8 to 1.3 (ie, the acute training load was approximately equal to the chronic training load), the risk of injury was relatively low. However, when the ACWR was $\geq 1.5$ (ie, the acute training load was much greater than chronic training load), the risk of injury increased exponentially (Figure 1). ${ }^{69}$ The protective effect of training appears to arise from 2 sources: Exposure to load allows the body to tolerate load, and training develops the physical qualities (eg, strength, prolonged

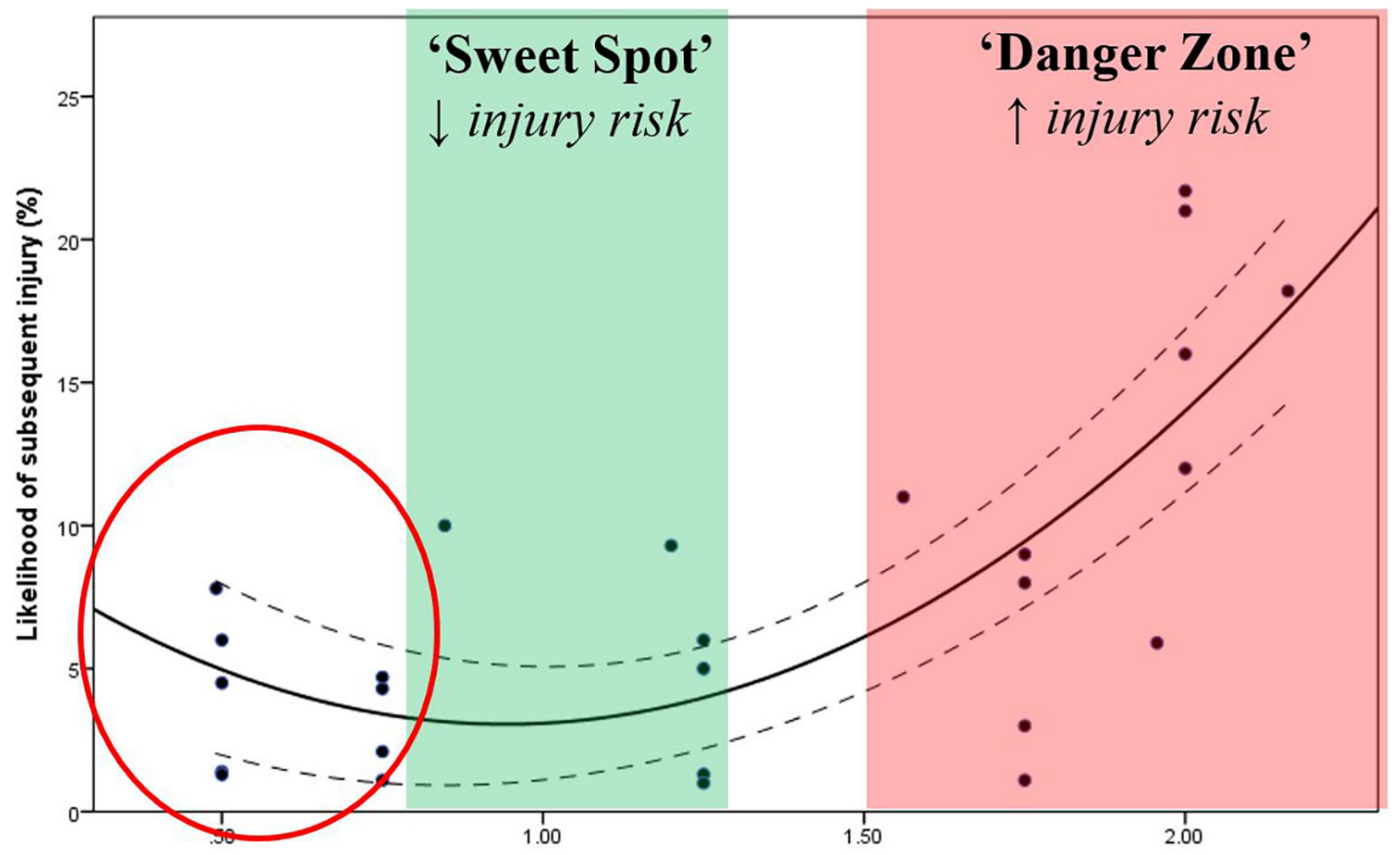

Acute:Chronic Workload Ratio

Figure 1 - The relationship between the acute:chronic-workload ratio and injury risk. Reprinted from Blanch P, Gabbett TJ. Has the athlete trained enough to return to play safely?: the acute:chronic workload ratio permits clinicians to quantify a player's risk of subsequent injury. Br J Sports Med. 2016;50(8):471-475. 
high-intensity-running ability, and aerobic fitness) that are associated with a reduced injury risk. ${ }^{79-81}$

One final point has been underemphasized in the training-loadinjury literature. Although "spikes" in training load may contribute to injuries, undertraining and "troughs" in training load may elicit similar negative consequences (Figure 1). For example, a $U$-shaped relationship between the number of maximal velocity exposures and injury risk has been shown in team-sport athletes; both overtraining and undertraining increased injury likelihood. ${ }^{81}$ The risk associated with exposure to maximal-velocity running is mitigated through exposure to high chronic training loads. ${ }^{82}$

These results have 3 important practical implications: High chronic training loads may protect against injury, athletes are better able to tolerate the high-intensity components of training if they have been exposed to higher chronic training loads, and the association of ACWR to injury risk is greater than either acute or chronic load in isolation.

\section{What Are the Challenges to Load Monitoring?}

Despite the benefits of athlete-load monitoring and the contribution of this area of sport science to athlete performance, there are limitations that warrant acknowledgment. All methods will have their own inherent strengths and limitations (see Table 1), which often depend on the context of the program to which they are applied and the objectives to be achieved.

Acceptable validity and reliability provide a minimum criterion for introduction. The standard of competition and the resources available will then influence the level of tolerance to issues related to expense, precision, ease of use, and staffing. While standards for applied practice should be similar to those expected in research, the choice of method may be influenced by the logistics of implementation. For example, sRPE is an inexpensive method that has the advantage of being able to quantify load irrespective of mode or location. In contrast, GPS time-motion analysis is only possible in an outdoor environment without overhead obstructions, requires hardware and software, and is restricted to locomotor movements and position tracking. It is, however, easily interpretable and can be used to prescribe training. Accelerometers, often integrated with other sensors in wearable devices, are similar in cost and hardware and software requirements and have the advantage of being independent of location and activity yet possess limitations in data interpretation and direct use to prescribe training.

Methods that directly quantify a unit of measure (eg, heart rate, distance, velocity, time) or are able to count occurrences or repetitions are easily interpretable and can be used to plan and prescribe training, as well as evaluate the demands of competition. The use of composite or derivative methods, typically measured in arbitrary units (eg, TRIMP derived from heart rate), metabolic power (derived from locomotor acceleration and deceleration), player load (derived from accelerometer acceleration), and SRPE (derived from perception of effort) adds more complexity to the interpretation of results but may bring more insight if analyzed correctly.

The objectives of a load-monitoring system and the context in which it will be applied may determine whether certain limitations are acceptable or not. A consistent and rigorous approach in a program over an extended period, even with a method that has some limitations, may provide meaningful data and influence practice, particularly if used in conjunction with other objective and subjective measures. Where comparisons are required between programs or sports or in a research context, then the method must be valid, reliable, and able to lead to more definitive, stand-alone interpretations.

\section{What Is the Future of Athlete-Load Monitoring?}

With the rate of development in miniature technology, wearable analytics tools, and apps it is relatively easy to predict that the sport scientist, athlete, and coach of the future will have access to more sensing solutions for predicting and coordinating performance than ever before. Market analysis has predicted that approximately 19 million fitness devices are likely to be sold per year, with the prediction to grow to 110 million in $2018 .{ }^{83}$ The athlete or team already has access to an array of internal and external markers of load. As technology becomes refined, the capacity for an integrated device (or clothing) to chart all aspects of mechanical, physiological, and psychological load in real time will become a reality. This could likely also include noninvasive technologies to measure blood and epigenetic variables (or responses) of load, as well as report calorific intake/expenditure and recovery processes (sleep, etc).

This brave new world will not only bring challenges around validity and reliability of measures but also raise significant issues around the interpretation of data. Some of these measurement issues have already been commented on in previous sections. However, the analytic models used will have to become more complex and will probably involve processes like pattern recognition, advanced neural networks, and machine learning. Implicit in these developments will be the need to ensure the integrity and cleanliness of data and the ecological validity of the models used to predict performance and injury risk. The challenge will be to ensure that the programmers can understand the context of the data (for each given sport/event) and that data can be presented in a meaningful manner to athletes and coaches. The ability to visualize data in a meaningful way will be crucial to ensure that training-load activities are able to inform and influence the coaching process. Studies from the field of business have shown that customizing and visualizing information correctly can increase the quality of information and potentially lead to faster and more accurate receipt and processing of that information. ${ }^{84}$ In order to develop more evidence-based approaches to training and given the ever-increasing business nature of elite sport, it will become increasingly necessary to develop more-effective data analysis and visualization solutions for coaches and athletes.

\section{Conclusion}

The capture and assessment of training- and competition-load data have a long history in elite sport, and the principles and practices of measuring external and internal load are relatively well defined. Within various sport-specific contexts, each variable presents its own strengths and limitations, all of which must be understood by the team supporting the athlete. The emergence of new technologies, coupled with new analytical approaches, suggests that ever-more-powerful tools to predict performance and risk of injury will soon be available. Nevertheless, to date no single measure has been identified that can accurately quantify the fitness and fatigue responses to training or predict performance..$^{1,10,11}$

While agreement may exist relating to the principal findings and recommendations in this paper, we acknowledge that the decision on which monitoring tools or techniques to use should remain with the professionals working in sport. This will allow 
- The informed selection of sport-specific combinations of internal- and external-load measures

- The ability to individualize load monitoring

- The determination of ACWR

- The delivery of reliable, accurate, and easily interpreted loadmonitoring information to the coach and athlete

thereby potentially

- Enhancing the athlete's, coach's, and support staff's knowledge of training and competition responses

- Assisting in improving the design of training and recovery programs

- Reducing the incidence of injury or illness

- Enhancing performance

\section{References}

1. Halson SL. Monitoring training load to understand fatigue in athletes. Sports Med. 2014;44(Suppl 2):S139-S147. PubMed doi:10.1007/ s40279-014-0253-Z

2. Townshend AD, Worringham CJ, Stewart IB. Assessment of speed and position during human locomotion using nondifferential GPS. Med Sci Sports Exerc. 2008;40(1):124-132. PubMed doi:10.1249/ mss.0b013e3181590bc2

3. Scott MT, Scott TJ, Kelly VG. The validity and reliability of global positioning systems in team sport: a brief review. J Strength Cond Res. 2016;30(5):1470-1490. PubMed doi:10.1519/JSC.0000000000001221

4. Jennings D, Cormack S, Coutts AJ, Boyd L, Aughey RJ. The validity and reliability of GPS units for measuring distance in team sport specific running patterns. Int J Sports Physiol Perform. 2010;5(3):328-341. PubMed doi:10.1123/ijspp.5.3.328

5. Varley MC, Fairweather IH, Aughey RJ. Validity and reliability of GPS for measuring instantaneous velocity during acceleration, deceleration, and constant motion. J Sports Sci. 2012;30(2):121-127. PubMed doi :10.1080/02640414.2011.627941

6. Akenhead R, French D, Thompson KG, Hayes PR. The acceleration dependent validity and reliability of $10 \mathrm{~Hz}$ GPS. J Sci Med Sport. 2014;17(5):562-566. PubMed doi:10.1016/j.jsams.2013.08.005

7. Jennings D, Cormack S, Coutts AJ, Boyd LJ, Aughey RJ. Variability of GPS units for measuring distance in team sport movements. Int $J$ Sports Physiol Perform. 2010;5(4):565-569. PubMed doi:10.1123/ ijspp.5.4.565

8. Akenhead R, Harley J, Tweddle S. Examining the external training load of an English Premier League football team with special reference to acceleration. J Strength Cond Res. 2016;30(9):2424-2432. PubMed doi:10.1519/JSC.0000000000001343

9. Ritchie D, Hopkins WG, Buchheit M, Cordy J, Bartlett JD. Quantification of training and competition load across a season in an elite Australian Football Club. Int J Sports Physiol Perform. 2016;11(4):474-479. PubMed doi:10.1123/ijspp.2015-0294

10. Mujika I. Quantification of training and completion loads in endurance sports: Methods and applications. Int J Sports Physiol Perf. 2017;12(Suppl 2):S2-9-S2-17. http://dx.doi.org/10.1123/ ijspp.2016-0403

11. Borresen J, Lambert MI. The quantification of training load, the training response and the effect on performance. Sports Med. 2009;39(9):779795. PubMed doi:10.2165/11317780-000000000-00000

12. Stone MH, Pierce KC, Sands WA, Stone ME. Weightlifting: program design. Strength Cond J. 2006;28(2):10-17.
13. McBride JM, McCaulley GO, Cormie P, Nuzzo JL, Cavill MJ, Triplett NT. Comparison of methods to quantify volume during resistance exercise. J Strength Cond Res. 2009;23(1):106-110. PubMed doi:10.1519/ JSC.0b013e31818efdfe

14. Garhammer J. Performance evaluation of Olympic weightlifters. Med Sci Sports. 1979;11(3):284-287. PubMed

15. Garhammer J. A review of power output studies of Olympic and powerlifting: methodology, performance prediction, and evaluation tests. J Strength Cond Res. 1993;7(2):76-89.

16. Gomez-Piriz PT, Sanchez ET, Manrique DC, Gonzalez EP. Reliability and comparability of the accelerometer and the linear position measuring device in resistance training. J Strength Cond Res. 2013;27(6):1664-1670. PubMed doi:10.1519/JSC.0b013e318269f809

17. Gleadhill S, Lee JB, James D. The development and validation of using inertial sensors to monitor postural change in resistance exercise. J Biomech. 2016;49(7):1259-1263. PubMed doi:10.1016/j. jbiomech.2016.03.012

18. Cormie P, McBride JM, McCaulley GO. Validation of power measurement techniques in dynamic lower body resistance exercises. $J$ Appl Biomech. 2007;23(2):103-118. PubMed doi:10.1123/jab.23.2.103

19. García-Ramos A, Stirn I, Strojnik V, et al. Comparison of the force-, velocity-, and power-time curves recorded with a force plate and a linear velocity transducer. Sports Biomech. 2016;15(3):329-341. PubMed doi :10.1080/14763141.2016.1161821

20. Hiskia G. Advanced electronic technology for real-time biomechanical analysis of weightlifting. In: Proceedings of the Weightlifting Symposium. Greece; 1993:89-95.

21. Huxley DJ, O'Connor D, Healey PA. An examination of the training profiles and injuries in elite youth track and field athletes. Eur J Sport Sci. 2014;14(2):185-192. PubMed doi:10.1080/17461391.2013.809153

22. Dennis RJ, Finch CF, Farhart PJ. Is bowling workload a risk factor for injury to Australian junior cricket fast bowlers? Br J Sports Med. 2005;39(11):843-846, discussion 843-846. PubMed doi:10.1136/ bjsm.2005.018515

23. Lyman S, Fleisig GS, Andrews JR, Osinski ED. Effect of pitch type, pitch count, and pitching mechanics on risk of elbow and shoulder pain in youth baseball pitchers. Am J Sports Med. 2002;30(4):463-468. PubMed

24. Visnes H, Aandahl HÅ, Bahr R. Jumper's knee paradox—jumping ability is a risk factor for developing jumper's knee: a 5-year prospective study. Br J Sports Med. 2013;47(8):503-507. PubMed doi:10.1136/ bjsports-2012-091385

25. Olsen SJ, Fleisig GS, Dun S, Loftice J, Andrews JR. Risk factors for shoulder and elbow injuries in adolescent baseball pitchers. Am J Sports Med. 2006;34:905-912. PubMed doi:10.1177/0363546505284188

26. Roos L, Taube W, Brandt M, Heyer L, Wyss T. Monitoring of daily training load and training load responses in endurance sports: what do coaches want? Schw Z Sport Sport. 2013;61(4):30-36.

27. Hulin BT, Gabbett TJ, Lawson DW, Caputi P, Sampson JA. The acute:chronic workload ratio predicts injury: high chronic workload may decrease injury risk in elite rugby league players. Br J Sports Med. 2016;50(4):231-236. PubMed doi:10.1136/bjsports-2015-094817

28. Clarsen B, Myklebust G, Bahr R. Development and validation of a new method for the registration of overuse injuries in sports injury epidemiology: the Oslo Sports Trauma Research Centre (OSTRC) Overuse Injury Questionnaire. Br J Sports Med. 2013;47(8):495-502. PubMed doi:10.1136/bjsports-2012-091524

29. Meeusen R, Duclos M, Foster C, et al. Prevention, diagnosis and treatment of the overtraining syndrome: joint consensus statement of the European College of Sport Science (ECSS) and the American College of Sports Medicine (ACSM). Eur J Sport Sci. 2013;13(1):1-24. doi:1 0.1080/17461391.2012.730061 
30. McNair DM, Lorr M, Droppleman LF. Profile of Mood States Manual. San Diego, CA: Education and Industrial Testing Service; 1992.

31. Saw AE, Kellmann, M, Main LC, Gastin PB. Athlete self-report measures in research and practice: considerations for the discerning reader and fastidious practitioner. Int J Sports Physiol Perf. 2017;12(Suppl 2) S2-127-S2-135. http://dx.doi.org/10.1123/ijspp.2016-0395

32. Borg G. Borg's Perceived Exertion and Pain Rating Scales. Champaign, IL: Human Kinetics; 1998.

33. Foster C. Monitoring training in athletes with reference to overtraining syndrome. Med Sci Sports Exerc. 1998;30(7):1164-1168. PubMed doi:10.1097/00005768-199807000-00023

34. Kellmann M, Kallus KW. The Recovery-Stress Questionnaire for Athletes. Champaign, IL: Human Kinetics; 2001.

35. Kellmann M, Kallus KW. Recovery-Stress Questionnaire for Athletes. In: Kallus KW, Kellmann M, eds. The Recovery-Stress Questionnaires: User Manual. Frankfurt am Main, Germany: Pearson Assessment \& Information; 2016:86-131.

36. Kellmann M, Kölling S, Hitzschke B. Das Akutmaß und die Kurzskala zur Erfassung von Erholung und Beanspruchung im Sport: Manual [The Acute Measure and Short Scale of Recovery and Stress for Sports: Manual]. Köln, Germany: Sportverlag Strauß; 2016.

37. Scott TJ, Black CR, Quinn J, Coutts AJ. Validity and reliability of the session-RPE method for quantifying training in Australian football: a comparison of the CR10 and CR100 scales. J Strength Cond Res. 2013;27(1):270-276. PubMed doi:10.1519/JSC.0b013e3182541d2e

38. Wallace LK, Slattery KM, Coutts AJ. The ecological validity and application of the session-RPE method for quantifying training loads in swimming. J Strength Cond Res. 2009;23(1):33-38. PubMed doi:10.1519/JSC.0b013e3181874512

39. Foster C, Daines E, Hector L, Snyder AC, Welsh R. Athletic performance in relation to training load. Wis Med J. 1996;95:370-374. PubMed

40. Foster C, Snyder A, Welsh R. Monitoring of training, warm up, and performance in athletes. In: Lehmann M, Foster C, Gastmann U, Keizer H, Steinacker JM, eds. Overload, Performance Incompetence and Regeneration in Sport. New York, NY: Kluwer Academic/ Plenum; 1999:43-51. doi:10.1007/978-0-585-34048-7_4

41. Gabbett TJ, Hulin BT, Blanch P, Whiteley R. High training workloads alone do not cause sports injuries: how you get there is the real issue. Br J Sports Med. 2016;50(8):444-445. PubMed doi:10.1136/ bjsports-2015-095567

42. Wallace LK, Slattery KM, Coutts AJ. A comparison of methods for quantifying training load: relationships between modelled and actual training responses. Eur J Appl Physiol. 2014;114(1):11-20. PubMed doi:10.1007/s00421-013-2745-1

43. Banister EW, Calvert TW, Savage MV, Bach T. A systems model of training for athletic performance. Austr J Sports Med Exerc Sci. 1975;7:57-61.

44. Busso T. Variable dose-response relationship between exercise training and performance. Med Sci Sports Exerc. 2003;35(7):1188-1195. PubMed doi:10.1249/01.MSS.0000074465.13621.37

45. Busso T, Carasso C, Lacour JR. Adequacy of a systems structure in the modeling of training effects on performance. J Appl Physiol. 1991;71(5):2044-2049. PubMed

46. Calvert TW, Banister EW, Savage MV, Bach T. A systems model of the effects of training on physical performance. IEEE Trans Syst Man Cybern. 1976;6:94-102. doi:10.1109/TSMC.1976.5409179

47. Fitz-Clarke JR, Morton RH, Banister EW. Optimizing athletic performance by influence curves. J Appl Physiol. 1991;71(3):1151-1158. PubMed

48. Morton RH, Fitz-Clarke JR, Banister EW. Modeling human performance in running. J Appl Physiol. 1990;69(3):1171-1177. PubMed
49. Busso T, Thomas L. Using mathematical modeling in training planning. Int J Sports Physiol Perform. 2006;1(4):400-405. PubMed doi:10.1123/ijspp.1.4.400

50. Mujika I, Busso T, Lacoste L, Barale F, Geyssant A, Chatard J-C. Modelled responses to training and taper in competitive swimmers. Med Sci Sports Exerc. 1996;28(2):251-258. PubMed doi:10.1097/00005768-199602000-00015

51. Wood RE, Hayter S, Rowbottom D, Stewart I. Applying a mathematical model to training adaptation in a distance runner. Eur J Appl Physiol. 2005;94(3):310-316. PubMed doi:10.1007/ s00421-005-1319-2

52. Hellard P, Avalos M, Lacoste L, Barale F, Chatard JC, Millet GP. Assessing the limitations of the Banister model in monitoring training. J Sports Sci. 2006;24(5):509-520. PubMed doi:10.1080/ 02640410500244697

53. Jobson SA, Passfield L, Atkinson G, Barton G, Scarf P. The analysis and utilization of cycling training data. Sports Med. 2009;39(10):833844. PubMed doi:10.2165/11317840-000000000-00000

54. Murray NB, Gabbett TJ, Townshend AD, Hulin BT, McLellan $\mathrm{CP}$. Individual and combined effects of acute and chronic running loads on injury risk in elite Australian footballers [published online ahead of print July 15, 2016]. Scand J Med Sci Sports.. doi:10.1111/ sms.12719 PubMed

55. Bowen L, Gross AS, Gimpel M, Li FX. Accumulated workloads and the acute:chronic workload ratio relate to injury risk in elite youth football players. Br J Sports Med. 2017;51(5):452-459. PubMed doi:10.1136/bjsports-2015-095820

56. Menaspà $P$. Are rolling averages a good way to assess training load for injury prevention? Br J Sports Med. 2017;51(7):618-619. PubMed doi:10.1136/bjsports-2016-096131

57. Williams S, West S, Cross MJ, Stokes KA. Better way to determine the acute:chronic workload ratio? [published online ahead of print September 20, 2016]. Br J Sports Med. doi:10.1136/bjsports-2016-096589 PubMed

58. Hunter JS. The exponentially weighted moving average. J Qual Technol. 1986;18:203-210.

59. Racinais S, Buchheit M, Bilsborough J, Bourdon PC, Cordy J, Coutts AJ. Physiological and performance responses to a training camp in the heat in professional Australian football players. Int $J$ Sports Physiol Perform. 2014;9(4):598-603. PubMed doi:10.1123/ ijspp.2013-0284

60. Kempton T, Sirotic AC, Coutts AJ. An integrated analysis of match-related fatigue in professional rugby league. J Sports Sci. 2015;33(1):39-47. PubMed doi:10.1080/02640414.2014.921832

61. Akubat I, Barrett S, Abt G. Integrating the internal and external training load in soccer. Int J Sports Physiol Perform. 2014;9(3):457-462. PubMed doi:10.1123/ijspp.2012-0347

62. Buchheit M, Racinais S, Bilsborough JC, et al. Monitoring fitness, fatigue and running performance during a pre-season training camp in elite football players. J Sci Med Sport. 2013;16(6):550-555. PubMed doi:10.1016/j.jsams.2012.12.003

63. Malone JJ, Lovell R, Varley MC, Coutts AJ. Unpacking the black box: applications and considerations for using GPS devices in sport. Int J Sports Physiol Perform. 2017;17(Suppl 2):S2-18-S2-26. http:// dx.doi.org/10.1123/ijspp.2016-0236

64. Taha T, Thomas SG. Systems modelling of the relationship between training and performance. Sports Med. 2003;33(14):1061-1073. PubMed doi:10.2165/00007256-200333140-00003

65. McGregor SJ, Weese RK, Ratz IK. Performance modeling in an Olympic 1500-m finalist: a practical approach. J Strength Cond Res. 2009;23(9):2515-2523. PubMed doi:10.1519/JSC. 0b013e3181bf88be 
66. Banister EW, Carter JB, Zarkadas PC. Training theory and taper: validation in triathlon athletes. Eur J Appl Physiol Occup Physiol. 1999;79(2):182-191. PubMed doi:10.1007/s004210050493

67. Pfeiffer M, Hohmann A. Applications of neural networks in training science. Hum Mov Sci. 2012;31(2):344-359. PubMed doi:10.1016/j. humov.2010.11.004

68. Windt J, Gabbett TJ. How do training and competition workloads relate to injury?: the workload-injury aetiology model. Br J Sports Med. 2017;51(5):428-435. PubMed doi:10.1136/bjsports-2016-096040

69. Blanch P, Gabbett TJ. Has the athlete trained enough to return to play safely?: the acute:chronic workload ratio permits clinicians to quantify a player's risk of subsequent injury. Br J Sports Med. 2016;50(8):471-475. PubMed doi:10.1136/bjsports-2015-095445

70. Gabbett TJ. Influence of training and match intensity on injuries in rugby league. J Sports Sci. 2004a;22(5):409-417. PubMed doi:10. 1080/02640410310001641638

71. Gabbett TJ, Domrow N. Relationships between training load, injury, and fitness in sub-elite collision sport athletes. J Sports Sci. 2007;25(13):1507-1519. PubMed doi:10.1080/02640410701215066

72. Gabbett TJ, Ullah S. Relationship between running loads and soft-tissue injury in elite team sport athletes. J Strength Cond Res. 2012;26(4):953-960. PubMed doi:10.1519/JSC.0b013e3182302023

73. Gabbett TJ. Reductions in pre-season training loads reduce training injury rates in rugby league players. Br J Sports Med. 2004b;38(6):743-749. PubMed doi:10.1136/bjsm.2003.008391

74. Hulin BT, Gabbett TJ, Blanch P, Chapman P, Bailey D, Orchard JW. Spikes in acute workload are associated with increased injury risk in elite cricket fast bowlers. Br J Sports Med. 2014;48(8):708-712. PubMed doi:10.1136/bjsports-2013-092524

75. Hulin BT, Gabbett TJ, Caputi P, Lawson DW, Sampson JA. Low chronic workload and the acute:chronic workload ratio are more predictive of injury than between-match recovery time: a two-season prospective cohort study in elite rugby league players. Br J Sports Med. 2016;50(16):1008-1012. PubMed doi:10.1136/bjsports-2015-095364
76. Gabbett TJ. The training-injury prevention paradox: should athletes be training smarter and harder? Br J Sports Med. 2016;50(5):273-280. PubMed doi:10.1136/bjsports-2015-095788

77. Soligard T, Schwellnus M, Alonso J, et al. How much is too much? (part 1) International Olympic Committee consensus statement on training and competition loads and the risk of injury. Br J Sports Med. 2016;50(17):1030-1041. PubMed doi:10.1136/bjsports-2016-096581

78. Windt J, Gabbett TJ, Ferris D, Khan KM. Training load-injury paradox: is greater preseason participation associated with lower in-season injury risk in elite rugby league players? Br J Sports Med. 2016; in press doi:10.1136/bjsports-2016-095973. PubMed

79. Gabbett TJ, Domrow N. Risk factors for injury in sub-elite rugby league players. Am J Sports Med. 2005;33(3):428-434. PubMed doi:10.1177/0363546504268407

80. Gabbett TJ, Ullah S, Finch CF. Identifying risk factors for contact injury in professional rugby league players - application of a frailty model for recurrent injury. J Sci Med Sport. 2012;15(6):496-504. PubMed doi:10.1016/j.jsams.2012.03.017

81. Malone S, Roe M, Doran DA, Gabbett TJ, Collins KD. Aerobic fitness and playing experience protect against spikes in workload: the role of the acute:chronic workload ratio on injury risk in elite Gaelic football [published online ahead of print August 24, 2016]. Int J Sports Physiol Perform. PubMed doi:10.1123/ijspp.2016-0090

82. Malone S, Roe M, Doran D, Gabbett TJ, Collins K. High chronic training loads and exposure to bouts of maximal velocity running reduce injury risk in Gaelic football. J Sci Med Sport. 2017;20(3):250-254. PubMed doi:10.1016/j.jsams.2016.08.005

83. Piwek L, Ellis DA, Andrews S, Joinson A. The rise of consumer health wearables: promises and barriers. PLoS Med. 2016;13(2):e1001953. PubMed doi:10.1371/journal.pmed.1001953

84. Zabukovec A, Jaklic J. The impact of information visualisation on the quality of information in business decision-making. Int J Technol Hum Interact. 2015;11(2):61-79. doi:10.4018/ijthi.2015040104 